\title{
SIMULATION MODELING AND ANALYSIS FOR IN-STORE MERCHANDIZING OF RETAIL STORES WITH ENHANCED INFORMATION TECHNOLOGY
}

\author{
Kanna Miwa \\ School of Commerce \\ 1-25 Astutanishi-cho, Nagoya Gakuin University \\ Astuta-ku, Nagoya, Aichi, 456-8612, JAPAN
}

\author{
Soemon Takakuwa \\ Graduate School of Economics \\ and Business Administration \\ Furo-cho, Nagoya University \\ Chikusa-ku, Nagoya, Aichi, 464-8601, JAPAN
}

\begin{abstract}
In this study a procedure of simulation modeling for instore merchandizing was used in order to examine customer flows in retail stores. One of the main objectives of this paper is to propose an approach of building a simulation model by making use of the POS data. The methods for identifying the arrival time and routing inside store are described, using daily POS data. This study primarily analyzed customer congestion and the utilization of the cash registers. Recently, IC tags are recognized in the fields of manufacturing and distribution systems as a powerful tool to reduce sales transaction time, with the assistance of the POS system. The proposed procedure was applied to the actual case. The results show that the customer flow can be examined easily, while the proposed procedure is useful for store management including cashiers scheduling and in-store merchandising.
\end{abstract}

\section{INTRODUCTION}

In this study, a simulation model of customer behavior was constructed and used to examine customer flows, particularly the customer waiting times at the cash register in a retail store. First, the customer's movements were examined, and then, their movement were simulated. The simulation model was designed and developed to make use of POS (Point of Sales) data, which included time of the sales, the customer type, the item code, and sales items.

POS software is usually recognized to correspond to merchandizing, in-store merchandizing, and operations (Tajima 2001). In-store merchandizing consists mainly of space allocation, planograms, and in-store promotions. In this study, in-store merchandizing and operations were treated as a model and in order to analyze customer flows and congestion in retail stores.

Preliminary simulation experiments indicated that when the customer arrived at the store, customer waiting time became longer, unless the additional cash registers and systems such as Radio Frequency Identification (RFID) were allocated to deal efficiency when lines became backed-up. Thus, from the standpoint of in-store merchandizing, scenarios on space allocations of items, IC (Integrated Circuit) tags, layout design were proposed as a way to reduce customer waiting time and congestion in a retail store. It is shown that the advanced information technology including IC tags allows for efficiency in transaction at the register in a retail store.

\section{SIMULATION STUDY FOR IN-STORE MERCHANDIZING}

\subsection{POS Data in the Retail Store}

Our proposed procedure assumed that the POS data was accumulated everyday and included the customer information on sales. By introducing an actual retail company, the characteristics of POS system could be described.

Retail and convenience stores face several problems. For example, customer demand is very different from each other, therefore, they must stock a wide variety of goods, which means that determining quantity becomes difficult for each store manager. In addition, the customers do not care for congestion when they come into a store. Evangelist et al. (2002) studied the relationship between waiting time and customer satisfaction and found that in order to reduce waiting time it is important that cash registers be used efficiently. Curin et al.(2005) employed simulation models to improve the utilization of the cash registers in restaurant on a university. There were several simulation studies of the restaurant model (Kharwat 1991, Jaynes and Hoffman 1994, Farahmand and Martinez 1996, Field et al. 1997, Brann and Kulick 2002). In addition, there were studies as passengers' waiting time at an international airport (Takakuwa and Oyama 2003) and patient flow in a hospital (Takakuwa and Shiozaki 2004). 


\section{Miwa and Takakuwa}

A POS system is composed of the POS register and the store controller. The POS register is installed in the store front and the store computer is installed in the backyard of the store. When a customer purchases an item, the store clerk scans the bar code with a scanner. All scanned data is collected at the POS register and stored as sales transaction in the store computer by LAN (Local Area Network) inside a store as POS data. Each day the data is processed at the opening and closing of the store. Next, the data is collected at a central data center via Internet and the collection of each store's data is analyzed. After the process of renewing records is finished, the aided information of POS data is refreshed at the local office until following day.

\subsection{Some Difficulties in using POS Data for Simulation}

A simulation-based approach in optimizing a grocery store's performance was discussed by Baydar (2003). There were several simulation models making use of POS data; for example, $\mathrm{Fu}$ and Piplani (2000) developed a model making use of POS data for the forecast. King and Moon (1999) and Joines et al. (2002) used POS data for the value of replenishment. Adams et al. (2005) used POS data in the spreadsheet simulation of Beer Game. Liu et al. (2006) and Venkateswaran et al. (2002) used POS data in a supply chain model. In the proposed model, the accumulated POS data from a convenience store were utilized.

Because the time marked at a POS register is one when a store clerk tallies a transaction, the customer would have spent a small amount of shopping and waiting time. Customer flow in a typical retail store is summarized in Figure 1, and the related times are specified including time marked in POS. In other words, it is necessary to obtain "Purchase of Sales" data instead of "Point of Sales" data. Hence, the times marked in POS data themselves cannot be used in the simulation and some modifications to the data should be performed before executing simulation.

A series of input data were arranged to perform the simulation, by making use of POS data. The simulation model was executed, and the output analyzed through the performed simulation.

\subsection{POS with IC Tags}

IC tags are a digital medium that uses radio frequency identification technology to keep track of items, and the tags automatically discriminate between various types of information through a wireless exchange of data between the built-in memory and the reader. As soon as a customer puts a basket of all items on the stand of the RFID at the register, the total amount for the items is displayed on the screen. Hence, by introducing IC tags, time to read bar codes of all items can be eliminated. The corresponding eliminated motions are shown in Figure 2. The Ministry of Economy, Trade and Industry of Japan (2007), and FamilyMart Co., Ltd. have conducted a series of experiments on this issue. According to our time-study, the transaction time at the register can be reduced by nearly half.

Through a series of simulation experiments, we examined how much customer waiting time can be minimized by leading the customer to the shortest register line, adopting IC tags, and changing allocation of items on the shelves.

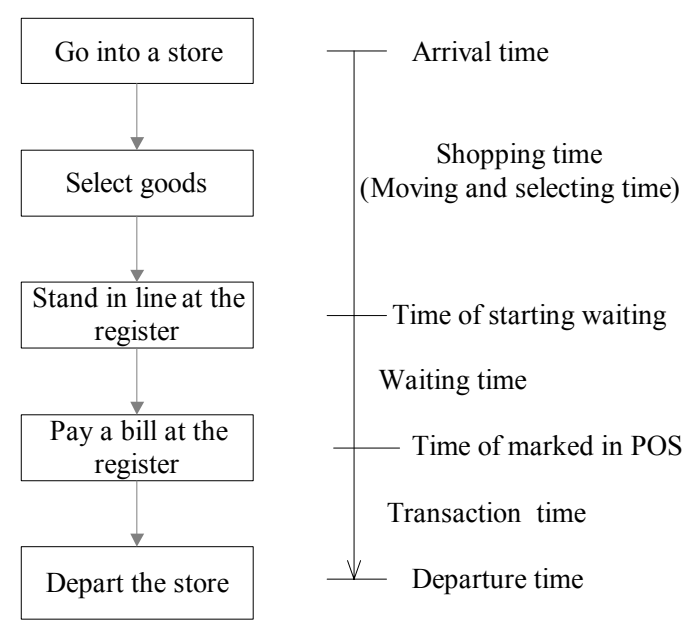

Figure 1: Customer Flow in a Retail Store

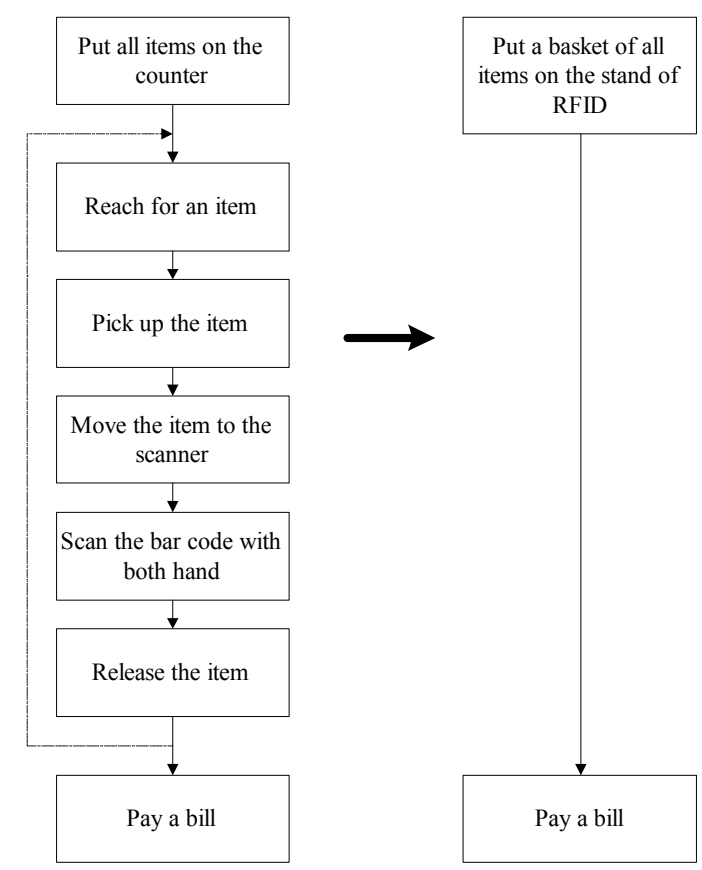

$\begin{array}{ll}\text { (a) With bar-code scanner } & \text { (b) With IC tag }\end{array}$

Figure 2: Bar-Code Scanner vs. IC Tag at the Register 


\section{SIMULATION MODEL FOR IN-STORE MERCHANDIZING}

\subsection{Description of the Simulation Models}

The simulation model proposed in this paper was constructed to represent customer flows inside a retail store. Using POS data is one of the major advantages is to perform simulation experiments. It is possible to represent customer flows and congestion inside the retail store by performing simulation model together with a series of POS data on one specific day. In addition, other scenarios can be examined by setting or changing parameters. Several procedures using POS data have been proposed in analyzing sales performance in a retail store. However, the procedure proposed in this paper can be used to find the controversial points in watching an animation of customer flows and congestion inside a retail store for either the current state of situation or scenarios. Of course, the performance of waiting time can be estimated by executing a simulation model.

Figure 3 shows the major flow of customers in a simulation model. First, the customer arrives at a store. Then they walk around in search of an item. After they decide on the items to buy, they select it from the gondola display, and they stand in line at the cash register. After a clerk scans and bags the goods, they pay the bill at the cash register and leave the store.

The simulation programs were written in Arena (Kelton et al. 2007). The proposed model comprised of three major logical subsystems, that is, time control, category allocation, and customer flow.

1. Time Control: this subsystem was designed to create entities or customers.

2. Category Allocation: this subsystem was designed to read the location of gondola display. This logic read file of "Category_Area". File was written the allocation of the area by Item group ID of 990 categories. If allocation of the category in the area was changed, we changed the contents in the file.

3. Customer Flow: this subsystem was designed to read a series of POS data and to move customers inside the retail store.

The stepwise procedure of simulation was as follows:

1. Create an entity and read the data of address of the group ID.

2. Read data of the address of group ID.

3. Assign a value of an entity.

4. Read purchased items from POS data.

5. Determine an arrival time by subtracting the estimated shopping time.

6. Let the customer arrive at the store at the predetermined time.
7. Let the customer visit the designated area and pick up the specified items.

8. Let the customer leave after sales transaction at the register.

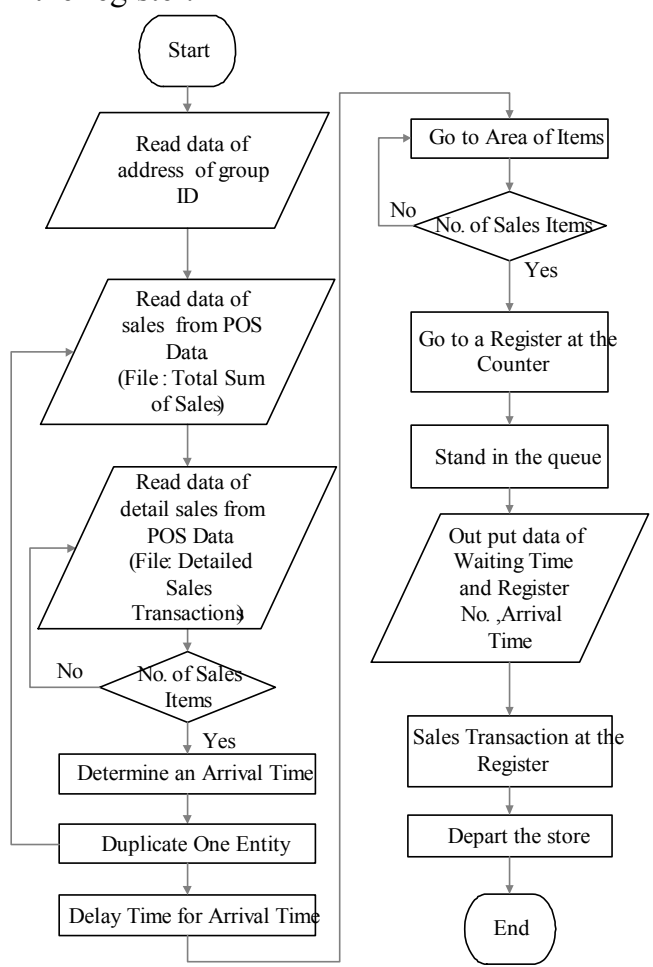

Figure 3: Flow of Simulation Model

\subsection{Performance Measures}

There are some possible scenarios more effective in easing congestion and shortening waiting time at the checkout counter. The performance measures were needed in order to compare the current situation to the specific scenarios. It was particularly necessary to define congestion of customers in the areas inside the retail store considering the number of customers picking up items as well as waiting in the queue for the checkout counter.

1. Waiting time per person: Customers wait for transaction in a line. Average waiting time per person, $W T$ (sec.) was given by:

$$
W T=\frac{1}{m} \sum_{i}^{m} W T_{i},
$$

where

$m$ : Number of customers (persons).

2. Congestion Degree: Many customers loitered around the checkout counters. Let $J_{k}$ be the number of the associated area to be counted as congestion for checkout counter No. $k$. The congestion degree for checkout counter No. $k, C D_{k}$, was defined by adding the time average number of 


\section{Miwa and Takakuwa}

customers in the waiting line and those in the area including those picking up items in the gondola:

$$
C D_{k}=\frac{1}{T}\left(\int_{0}^{T} Q_{k}(t) d t+\sum_{j=1}^{J_{k}} \int_{0}^{T} S_{k j}(t) d t\right),
$$

where

$j$ : Associated consecutive area No. for checkout counter No. $k\left(j=1,2, \ldots, J_{k}\right)$.

$k$ : Checkout counter No. $(k=1,2, \ldots, K)$.

$Q_{k}(t)$ : The number of customers in the waiting line for checkout counter $k$ at any time instant $t$ (persons).

$S_{k j}(t)$ : The number of customers located at the area No. $j$ for checkout counter No. $k$ except those in the waiting line at time $t$ (persons).

$T$ : Simulation length (sec.).

\section{APPLICATION}

\subsection{Description of a Retail Store}

FamilyMart is a convenience store that provides a wide variety of consumable products. The FamilyMart Group comprises 23 companies including FamilyMart Co., Ltd., 11 subsidiaries, and 11 affiliates. Centered at its core business is the operation of a network of 12,452 convenience stores (as of end of February 2006) in Japan and other countries. The group engages in retailing business that provides customers with high-value-added merchandise and friendly hospitality.

In order to build the simulation model inside store, we conducted a preliminary analyses of the intended convenience store. The store description is as follows:

Location : Nagoya University Campus.

Opening hours: 7:00-23:00.

Next, the POS data collected from the FamilyMart at Nagoya University was analyzed. Area division inside the store is illustrated in Figure 4. As many students congregate during the week because of classes, there were many customers on weekday, while on the weekend were about half as many as a weekday. The ranking sales of item group is summarized in Table 1 and Figure 5 shows a list of gondola display and sales volume.

\subsection{Parameters of Simulation Models}

As shown in Figure 1, regarding customer time in a store included walking around, item selection, and transaction times, which were all analyzed. Based on time-study, customer movement and selection times were analyzed by using the Arena input analyzer. In addition, the transaction time had a correlation with the number of purchased items, a regression analysis was applied to uncover the duration of scanning an item, payment, and bagging of items.

Now, let $t_{S}$ represent scanning an item time, and $n$ the number of items purchased, and scanning an item time $t_{S}$ can be estimated as follows:

$$
t_{S}=2.43 n+0.03 \text {. }
$$

Letting $t_{T}$ equal duration of bagging items and payment at a register, the time at a register can be estimated as

$$
t_{T}=6.76 n+14.76 \text {, }
$$

where $n$ is the number of purchased items for customers.

The model inside the store consisted of several parameters and Table 2 represents the list of parameters. Each customer was modeled from several attributes. Arrival time of each customer was created based to the POS data. Time marked in POS was at the beginning of a transaction at the checkout counter. Hence, it was necessary to estimate the arrival time at the retail store. In the proposed procedure, times to move around and select items for purchase were estimated by a regression analysis, based on a time-study. Movement time and item selection time were estimated with fit distributions by an Arena Input analyzer. The scanning, bagging and payment times were adapted as triangular distributions using a regression analysis.

Two kinds of POS data files were used. One was the "Total_Sum_of_Sales" and the other was "Detailed_Sales_Transactions." The "Total_Sum_of_Sales" represented each customer sale, as shown in Table 3 . The "Detailed Sales Transactions" reflected the detailed sale of each customer as shown in Table 4. For example, the first row of "Total_Sum_of_Sales" shows the first customer in this store on January 21th, 2008. The customer bought three items at 12:00 at register No. 4. The customer was a male in his thirties and the total sum of the sale was 576 yen. In addition "Detailed_Sales_Transactions" represented contents of sales each customer. The customer bought "Omelet-cheesecurry rice-ball" which was a rice-ball from item group ID 41 and "Salad" and "Chocolate".

It was necessary to define area at a retail store in order to evaluate congestion. In this study, area divisions are set inside a store, as shown in Figure 4. The model included the address of items to animate customer flows. According to the POS data, customers moved between areas. Table 5 shows the contents of items by group ID. For example, the item group ID for "Rice Ball" and "1st delivery" is labeled as 4-1. Next, Table 6 shows the number of areas. In the case of delivery 4-1, the item was displayed in Area No. 2.

\subsection{Performance Measures for Congestion Degree}

As mentioned in Section 3.2 above, performance measures for congestion degree need to be defined. Hence, the number of customers in front of checkout counter No. 1 


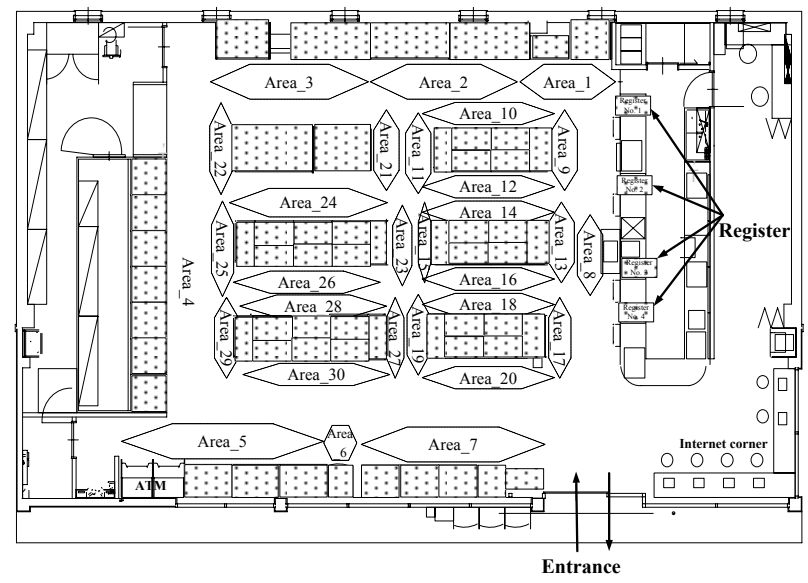

Figure 4: Area Division at a Retail Store

Table 1: Ranking Sales of Item Group (2008/01/21)

\begin{tabular}{c|c|c|c}
\hline \multirow{2}{*}{ Ranking } & Item Group & $\begin{array}{c}\text { Total Sales } \\
\text { Volume (Jyen) }\end{array}$ & $\begin{array}{c}\text { Percentage } \\
(\%)\end{array}$ \\
\hline 1 & Deep-fried food & 47796 & 6.73 \\
2 & Lunch boxes - 2 & 38919 & 5.48 \\
3 & Tea, Oolong tea & 34753 & 4.89 \\
4 & Snack noodles - 1 & 31896 & 4.49 \\
5 & Coffee & 27038 & 3.80 \\
6 & Sweetened buns, Bun -1 & 24957 & 3.51 \\
7 & Rice Ball - 2 & 24656 & 3.47 \\
8 & Cup noodles & 24338 & 3.42 \\
9 & Milk-based drinks & 22354 & 3.15 \\
10 & Chocolates & 20580 & 2.90 \\
$:$ & $:$ & 710713 & $:$ \\
\hline & Tota 1 &
\end{tabular}

was expressed as the sum of the number of customers waiting for checkout counter No. 1 and those selecting and picking up items in Area 02 and Area 10:

$C D_{1}=N Q($ Regi_01) + NSTO (Area_02 Storage $)+$ NSTO (Area_10 Storage).

Similarly, the numbers of customers in front of the other checkout counters are expressed as:

$$
\begin{aligned}
C D_{2}= & \text { NQ }(\text { Regi_02) }+ \text { NSTO (Area_12 Storage })+ \\
& \text { NSTO (Area_14 Storage }) . \\
C D_{3}= & \text { NQ }(\text { Regi_03) }+ \text { NSTO (Area_16 Storage) }+ \\
& \text { NSTO (Area_18 Storage }) . \\
C D_{4}= & \text { NQ }(\text { Regi_04) }+ \text { NSTO }(\text { Area_20Storage }) .
\end{aligned}
$$

\subsection{Animation Model}

The animation model was constructed with Arena 3D player, as shown in Figure 6. The entity picture was set for each type of customers, and the location of congestion inside the retail shop can be identified easily by viewing the animation of the simulation model.

\subsection{Scenarios}

Simulation technology provides a very powerful way to

\begin{tabular}{|c|c|}
\hline Name & Parameter \\
\hline Arrival time & Time of marked in POS - (Select time * $n+$ Moving time $*(n+2))$ \\
\hline Moving time & $7+\mathrm{WEIB}(14.90,0.91)$ \\
\hline Select time & $0.999+\mathrm{EXPO}(23.40)$ \\
\hline Scan Time & TRIA $(1,2.43 * n+0.03,2.43 * n+0.03+3 * 3.17)$ \\
\hline Transaction Time & TRIA $(7,6.76 * n+14.76,6.76 * n+14.76+3 * 9.31)$ \\
\hline Name & POS data : File Name \\
\hline Customer No. & Total_Sum_of_Sales \\
\hline Time of Salse & Total_Sum_of_Sales \\
\hline Cutomer Type & Total_Sum_of_Sales \\
\hline No.of Total Sales Items & Total_Sum_of_Sales \\
\hline Item Group ID of Sales & Detailed_Sales_Transactions \\
\hline No. of Sales Items & Detailed Sales Transactions \\
\hline Name & File Name \\
\hline Area No. of Item Group ID & Category Area \\
\hline
\end{tabular}
move from an "as-is" system to an ultimate "to-be" sys-

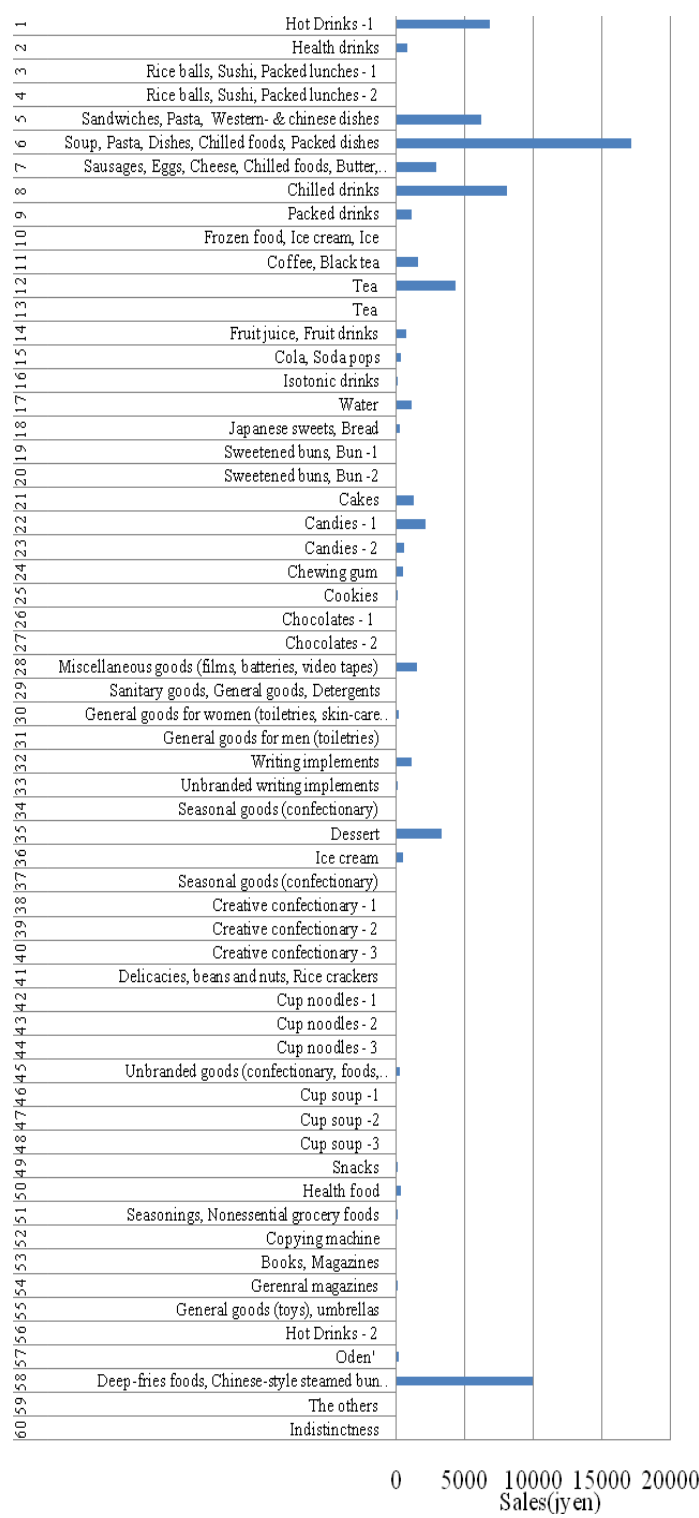

Figure 5: List of Gondola Display and Sales Volume

Table 2: POS data and Selected Parameters 


\section{Miwa and Takakuwa}

Table 3: POS Data Extracted (File Name : "Total Sum of Sales")

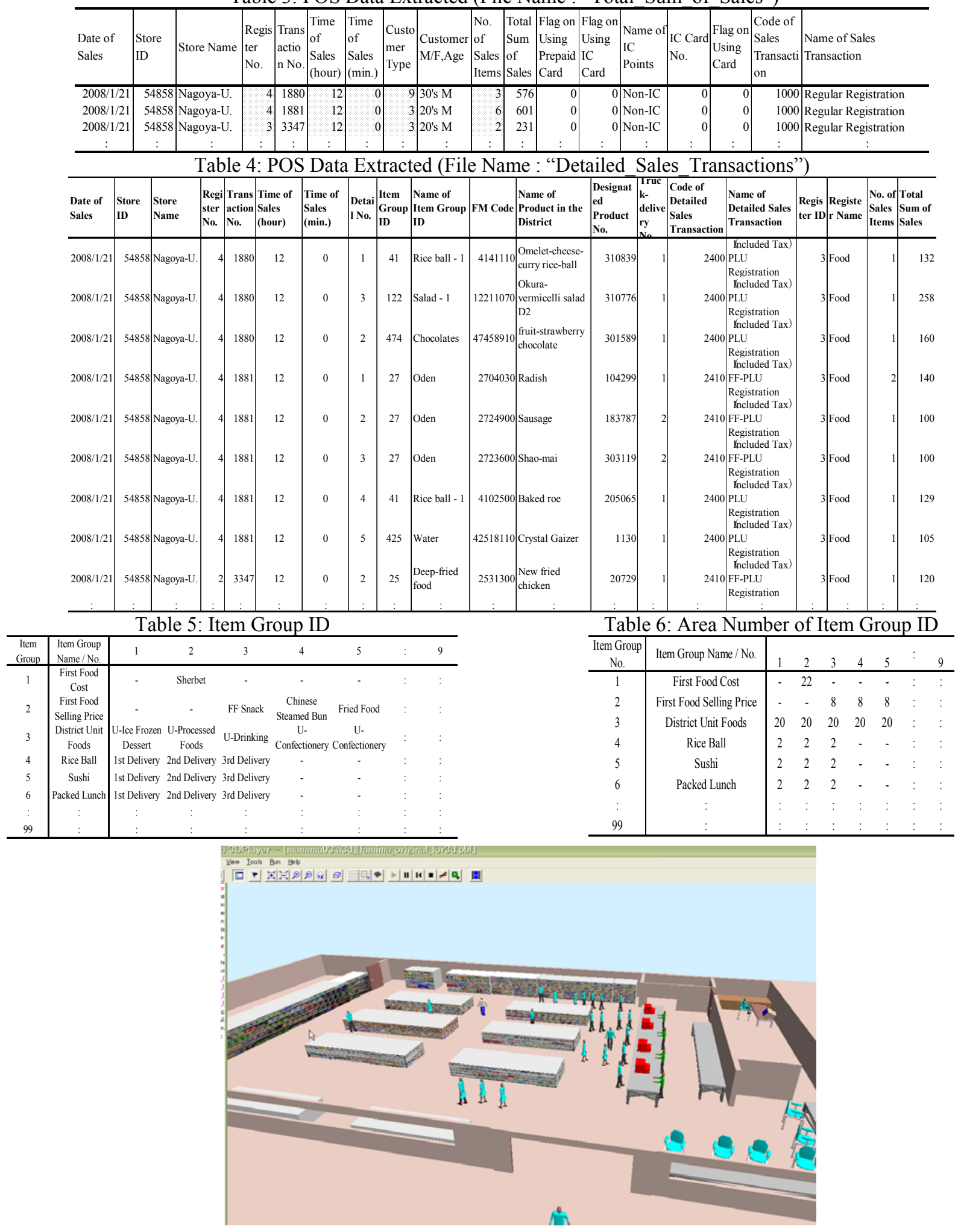

Figure 6: Animation of the Model 


\section{Miwa and Takakuwa}

tem. An "as-is" system accurately captures the behavior of the original system and then hypothetically changes the system until the best scenario is identified. By conducting a "what-if" analysis, the simulation analysis should be able to discover a far determined without the technology (Profozich, 1998). Table 7 shows several scenarios applied in this study. The "as-is model" represents the behavior of a current environment. The "to-be IC", the "to-be Line," the "to-be_IC \& Line," and the "to-be_Allocation" represent ideal models that we and the customers seek. However, the baseline "as-is model" does not change.

The number of customers at the store reaches a peak during twelve noon and 1 p.m. During these peak hour, the volume of sales accounts for approximately 18 percent of all the sales volume in the day with the opening hours being from 7 a.m. through 11 p.m. Therefore, the following analysis focused on the issue of how to ease congestion of specific areas inside the retail store at the peak hour.

From the preliminary study, the following matters were identified as the question at issue:

1. Customers had to wait in lines for the checkout counters too long.

2. The gondola shelves obstructed the view for the customers waiting for the checkout counter No. 1 from seeing the other checkout counters, that is, No. 2 through No.3.

3. The degree of congestion was the severest in the area of the waiting line for the checkout counter No. 1, because the other customers choosing and picking up items were in the same area and the gondola shelves obstructed the view, as mentioned in 2 .

Besides the "as-is" scenario, four "to-be" scenarios were adopted in seek ways to ease congestion inside the retail store, as summarized in Table 7:

1. The "to-be_IC" scenario: By introducing an IC tag as an attachment to each item and using electronic money, the transaction time at the register was shortened.

2. The "to-be_Line" scenario: At present, many customers tend to wait in No.1 line for checkout. Customers were routed to other waiting lines in an equal manner.

3. The "to-be IC \& Line" scenario: Both the policies of "to-be IC" and "to-be Line" scenarios were adopted.

4. The "to-be_Allocation" scenario: By changing the allocation of designated items at the gondola shelves at Area_02 to Area_30, congestion at Area_02 could be eased, because many customers buy those items.
Table 7: Scenarios

\begin{tabular}{l|l|c}
\hline \multicolumn{1}{c|}{ Scenario } & \multicolumn{1}{|c}{ Description } & \multicolumn{1}{c}{ Parameter } \\
\hline as-is & Actual State & - \\
to-be_IC & Using the items putted IC tag. & Transaction Time: TRIA $(12.6,14,15.4)$ \\
to-be_Line & Customers line in the most shortest queue. & - \\
to-be_IC \& Line & To_Be_IC and To_Be_Line & Transaction Time: TRIA $(12.6,14,15.4)$ \\
to-be_Allocation & Change of the Allocation. The Area_02 and Area_30 & - \\
\hline
\end{tabular}

\subsection{Selected Simulation Analysis}

1. Number of inflow customers in the area: The numbers of customers entering in the areas are shown in Figure 7. The numbers of customers entering area numbers $2,3,4,8$, and 10 were more than those entering in other numbers.

2. Number of customer movements between areas: Analytic results on customer movements between areas are shown in Figure 8. It was observed that the customer moved quite often especially between Area_02 and Area_03, Area_04, and Area_08.

3. Customer Waiting Time: Figure 9 shows the $95 \%$ confidence interval on the average waiting time during peak hours (12:00 13:00). At present, the average waiting time is approximately two minutes in line for checkout counter No. 1. By introducing IC tags and electronic money, the average waiting time could be reduced to 13 seconds, that is, reduced by approximately 94 percent. Next, by letting customers route to other waiting lines equally, the average waiting time could be reduced by approximately 55 percent.

4. Degree of Congestion: Figure 10 shows the $95 \%$ confidence interval on the degree of congestion during the peak hour. Regarding congestion in front of checkout counters, the congestion degree could be reduced by 67 percent by introducing IC tags and electronic money. In addition, the congestion degree could be reduced by 41 percent by changing customer routing to waiting lines and could be reduced by 64 percent by introducing both IC tags - electronic money and the way of changing customer routing. By changing the location of item groups in gondola displays, the congestion degree could be reduced by approximately 20 percent.

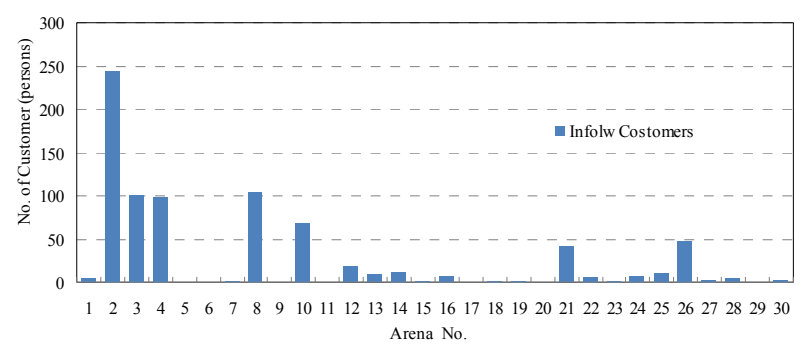

Figure 7: Number of Inflow Customers in the Area 


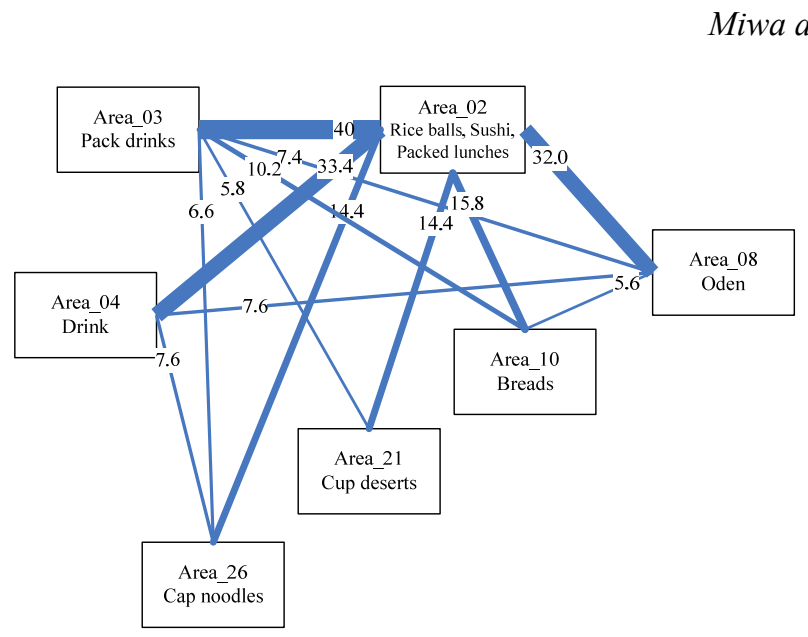

Figure 8: Average No. of Customers Transfer between Areas

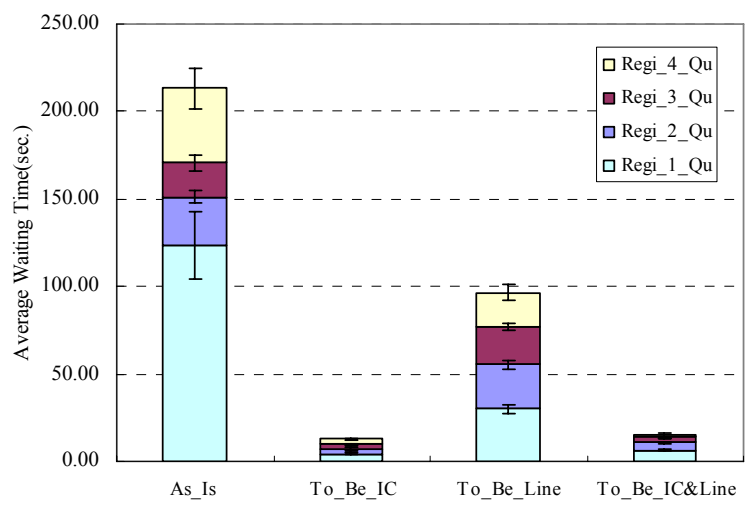

Figure 9: 95\% Confidence Interval on the Average Waiting Time

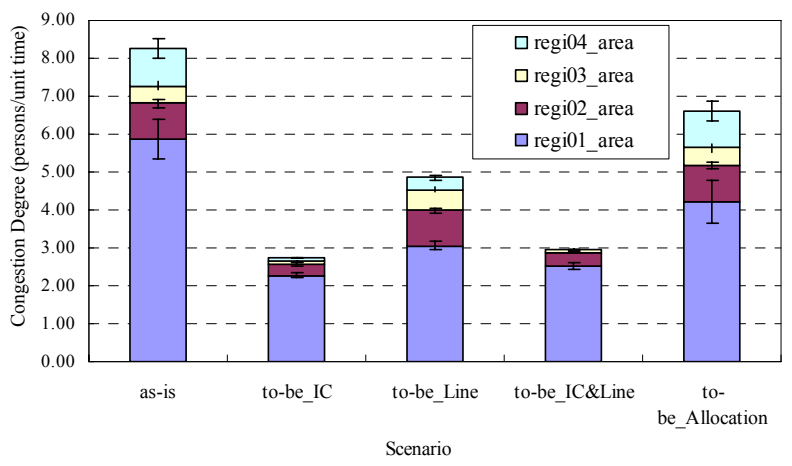

Figure 10: Congestion Degree

\section{CONCLUSIONS}

A stepwise procedure of simulation modeling for in-store merchandizing was described as a way to examine customer flows in retail stores. An approach to building a simulation model was proposed by making use of the POS data. The performance measure of the degree of congestion inside a

retail store was introduced as a way to evaluate alternatives. Recently, IC tags and electronic money were recognized as a powerful tool to reduce sales transaction time, used together with a POS system. The proposed procedure corresponded to these recent types of advanced information technology.

The proposed procedure was applied to an actual case. A convenience store on the campus of Nagoya University was modeled through simulation in order to examine customer flows and congestion. The results show that the customer flows can be examined easily and the proposed procedure useful for store management including cashiers scheduling and in-store merchandising. The advanced information technology including IC tags allows for efficiency in transaction at the register in a retail store.

\section{ACKNOWLEDGMENTS}

The authors wish to thanks Mr. Ueda, Mr. Takahashi, Mr. Mutsumi, Mr. Fujita, and Mr. Nihei of FamilyMart Co., Ltd. for acknowledgment in this research.

\section{REFERENCES}

Adams, J., J. Flatto, and L. Gardner. 2005. Combining Hands-On, Spreadsheet and Discrete Event Simulation to Teach Supply Chain Management. In Proceedings of the 2005 Winter Simulation Conference, ed. M.E. Kuhl, N. M. Steiger, F. B. Armstrong, and J. A. Joines, 23292337. Piscataway, New Jersey: Institute of Electrical and Electronics Engineers, Inc.

Bayder, C. 2003. Agent-Based Modeling and Simulation of Store Performance for Personalized Pricing. In Proceedings of the 2003 Winter Simulation Conference, ed. S.Chich, P. J. Sanchez, D. Ferrin, and D. J. Morrice, 1759-1764. Piscataway, New Jersey: Institute of Electrical and Electronics Engineers, Inc.

Brann, D. M. and B. C. Kulick. 2002. Simulation of Restaurant Operations Using the Restaurant Modeling Studio. In Proceedings of the 2002 Winter Simulation Conference, ed. E. Yucesan, C.-H. Chen, J. L. Snowdon, and J. M. Charnes, 1448-1453. Piscataway, New Jersey: Institute of Electrical and Electronics Engineers, Inc.

Curin, S. A., J. S. Vosko, E. W. Chan, and O. Tsimhoni. 2005. Reducing Service Time at a Busy Fast Food Restaurant on Campus. In Proceedings of the 2005 Winter Simulation Conference, ed. M.E. Kuhl, N. M. Steiger, F. B. Armstrong, and J. A. Joines, 2628-2635. Piscataway, New Jersey: Institute of Electrical and Electronics Engineers, Inc.

Evangelist, S., B. Godwin, J. Johnson, V. Conzola, R. Kizer, S. Young-Helou, and R. Metters. 2002. Linking Marketing and Operations: An Application at Blockbuster,Inc. Journal of Service Research. Vol.5. No. 2. 91-100. SAGE Publications. 
Farahmand, K. and A. F. G. Martinez. 1996. Simulation and Animation of the Operation of a Fast Food Restaurant. In Proceedings of the 1996 Winter Simulation Conference, ed. J. M. Charnes, D. J. Morrice, D. T. Brunner, and J. J. Swain, 1264-1271. Piscataway, New Jersey: Institute of Electrical and Electronics Engineers, Inc.

Filed, A., M. McKnew, and P. Kiessler. 1997. A Simulation comparison of buffet restaurants: applying Monte Carlo modeling. Cornell Hotel and Restaurant Administration Quarterly, 38(6): 68-79.

Fu, F. and R. Piplani. 2000. Multi-Agent Enabled Modeling And Simulation Towards Collaborative Inventory Management In Supply Chains. In Proceedings of the 2000 Winter Simulation Conference, ed. J. A. Joines, R. R. Barton, K. Kang, and P. A. Fishwick,1763-1771. Piscataway, New Jersey: Institute of Electrical and Electronics Engineers, Inc.

Jaynes, S. L. and J. O. Hoffman. 1994. Discrete Event Simulation for Quick Service Restaurant Traffic Analysis, In Proceedings of the 1994 Winter Simulation Conference, ed. J. D. Tew, S. Manivannan, D. A. Sadowski, and A. F. Seila, 1061-1066. Piscataway, New Jersey: Institute of Electrical and Electronics Engineers, Inc.

Joines, J. A., D. Gupta, M. A. Gokce, R. E. King, and M. G. Kay. 2002. Supply Chain Multi-Objective Simulation Optimization. In Proceedings of the 2002 Winter Simulation Conference, ed. E. Yucesan, C.-H. Chen, J. L. Snowdon, and J. M. Charnes, 1306-1314. Piscataway, New Jersey: Institute of Electrical and Electronics Engineers, Inc.

Kelton, W. D., R. P. Sadowski, and D. T. Sturrock. 2007. Simulation with ARENA. 4th ed. New York: McGrawHill, Inc.

Kharwat, A. K. 1991. Computer Simulation: an Important Tool in the Fast- Food Industry. In Proceedings of the 1991 Winter Simulation Conference, ed. B. L. Nelson, W. D. Kelton, and G. M. Clark, 811-815. Piscataway, New Jersey: Institute of Electrical and Electronics Engineers, Inc.

King, R. E. and K. Moon. 1999. Quick Response Replenishment: A Case Study. In Proceedings of the 1999 Winter Simulation Conference, ed. P. A. Farrington, H.B. Nembhard, D. T. Sturrock, and G. W. Evans, 1341-1349. Piscataway, New Jersey: Institute of Electrical and Electronics Engineers, Inc.

Liu, R., A. Kumar, and A. Stenger. 2006. Simulation Results for Supply Chain Configurations Based on Information Sharing. In Proceedings of the 2006 Winter Simulation Conference, ed. L. F. Perrone, F. P. Wieland, J. Liu, B. G. Lawson, D. M. Nicol, and R. M. Fujimoto, 627-635. Piscataway, New Jersey: I Institute of Electrical and Electronics Engineers, Inc.

Profozich, D. 1998. Managing Change with Business Process Simulation. New Jersey: Prentice Hall PRT.
Tajima, Y. 2001. In-store Merchandizing.Tokyo: Business Sha Co. Ltd. Tokyo. (in Japanese)

Takakuwa, S. and H. Shiozaki. 2004. Functional Analysis for Operating Emergency Department of a General Hospital. In Proceedings of the 2004 Winter Simulation Conference, ed. R. G. Ingalls, M. D. Rossetti, J. S. Smith, and B. A. Peters, 2003-2011. Piscataway, New Jersey: Institute of Electrical and Electronics Engineers, Inc.

Takakuwa, S. and T. Oyama. 2003. Simulation Analysis of International Flows in an Airport Terminal. In Proceedings of the 2003 Winter Simulation Conference, ed. S. Chich, P. J. Sanchez, D. Ferrin, and D. J. Morrice, 1627-1633. Piscataway, New Jersey: Institute of Electrical and Electronics Engineers, Inc.

The Ministry of Economy, Trade, and Industry of Japan, 2007. Experiments on IC Tags. Available via <http://www.meti.go.jp/policy/it_poli cy/tag/> [accessed March 31, 2008].

Venkateswaran, J. and Y. Son, and B. Kulvatunyou. 2002. Investigation of Influence of Modeling Fidelities on Supply Chain Dynamics. In Proceedings of the 2002 Winter Simulation Conference, ed. E. Yucesan, C.-H. Chen, J. L. Snowdon, and J. M. Charnes, 1183-1191. Piscataway, New Jersey: Institute of Electrical and Electronics Engineers, Inc.

\section{AUTHOR BIOGRAPHIES}

KANNA MIWA is a assistant professer in the School of Commerce at the Nagoya Gakuin University in Japan. She received her B. Sc. and M. Sc. degrees in Economics from Nagoya University in 2000 and 2003, respectively. She received her Ph.D. from the Graduate School of Economics and Business Administration at Nagoya University in 2006. Her research interests include optimization of logistics, supply chain, and manufacturing systems.

SOEMON TAKAKUWA is a Professor in the Graduate School of Economics and Business Administration at Nagoya University in Japan. He received his B. Sc. and M. Sc. degrees in industrial engineering from Nagoya Institute of Technology in 1975 and from Tokyo Institute of Technology in 1977 respectively. His Ph.D. is in industrial engineering from The Pennsylvania State University. He holds a Doctorate of Economics from Nagoya University. His research interests include optimization of manufacturing and logistics systems, management information system and simulation analysis on these systems including hospitals. He has prepared the Japanese editions of both Introduction to simulation using SIMAN and Simulation with $A R E N A$. He has been serving concurrently as the senior staff of Department of Hospital Management Strategy and Planning at Nagoya University Hospital. 